\title{
Simulation models of technological innovation: a review
}

Citation for published version (APA):

Windrum, P. (1999). Simulation models of technological innovation: a review. MERIT, Maastricht Economic Research Institute on Innovation and Technology. MERIT Research Memoranda No. 005 https://doi.org/10.26481/umamer.1999005

Document status and date:

Published: 01/01/1999

DOI:

10.26481/umamer.1999005

Document Version:

Publisher's PDF, also known as Version of record

\section{Please check the document version of this publication:}

- A submitted manuscript is the version of the article upon submission and before peer-review. There can be important differences between the submitted version and the official published version of record.

People interested in the research are advised to contact the author for the final version of the publication, or visit the DOI to the publisher's website.

- The final author version and the galley proof are versions of the publication after peer review.

- The final published version features the final layout of the paper including the volume, issue and page numbers.

Link to publication

\footnotetext{
General rights rights.

- You may freely distribute the URL identifying the publication in the public portal. please follow below link for the End User Agreement:

www.umlib.nl/taverne-license

Take down policy

If you believe that this document breaches copyright please contact us at:

repository@maastrichtuniversity.nl

providing details and we will investigate your claim.
}

Copyright and moral rights for the publications made accessible in the public portal are retained by the authors and/or other copyright owners and it is a condition of accessing publications that users recognise and abide by the legal requirements associated with these

- Users may download and print one copy of any publication from the public portal for the purpose of private study or research.

- You may not further distribute the material or use it for any profit-making activity or commercial gain

If the publication is distributed under the terms of Article $25 \mathrm{fa}$ of the Dutch Copyright Act, indicated by the "Taverne" license above, 
Simulation models of technological innovation: A Review

\author{
Paul Windrum
}

\author{
MERIT \\ University of Maastricht \\ The Netherlands
}

Correspondence address: $\quad$ Dr. P. Windrum

MERIT

University of Maastricht

Togersesetraat 49

PO Box 616

6200 MD Maastricht

The Netherlands

E-mail: p.windrum@merit.unimaas.nl 


\section{Abstract}

The use of simulation modelling techniques in studies of technological innovation dates back to Nelson and Winter's 1982 book 'An Evolutionary Theory of Economic Change' and is an area which has been steadily expanding ever since. Four main issues are identified in reviewing the key contributions that have been made to this burgeoning literature. Firstly, a key driver in the construction of computer simulations has been the desire to develop more complicated theoretical models capable of dealing with the complex phenomena characteristic of technological innovation. Secondly, no single model captures all of the dimensions and stylised facts of innovative learning. Indeed this paper argues that one can usefully distinguish between the various contributions according to the particular dimensions of the learning process which they explore. To this end the paper develops a taxonomy which usefully distinguishes between these dimensions and also clarifies the quite different perspectives underpinning the contributions made by mainstream economists and non-mainstream, neo-Schumpeterian economists.

This brings us to a third point highlighted in the paper. The character of simulation models which are developed are heavily influenced by the generic research questions of these different schools of thought. Finally, attention is drawn to an important distinction between the process of learning and adaptation within a static environment, and dynamic environments in which the introduction of new artefacts and patterns of behaviour change the selective pressure faced by agents. We show that modellers choosing to explore one or other of these settings reveal their quite different conceptual understandings of 'technological innovation'.

Keywords: computer simulations, learning, technological innovation, neo-Schumpeterian economics 


\section{Introduction : Learning by adaptive agents in complex environments}

Economic studies of technical innovation frequently equate technological change and innovation with the development of new products and processes and/or the improvement of existing products and processes. Although not complete, economists from David Ricardo (Principles, 1817) onwards have found this definition a fruitful first approximation. Of course the study of technological innovation, as economists are well aware, is as concerned with cognition as it is with artefacts. Technology studies examine the production of new knowledge, competencies and behaviour, and the impact which these have on the wider social milieu. A useful way of capturing these artefactual and cognitive dimensions is to consider technological innovation as a learning process in which social actors, or 'agents', seek new ways of doing things and producing things (tangible and intangible). Through this learning process the character and behaviour of social agents adapts and changes over time. What is more, the learning processes of different groups of social agents can influence each other in recursive, highly complex ways.

We shall highlight four key aspects of the current literature. To begin with, the increasing use of computer simulations reflects a growing desire to develop more complicated models capable of analysing the complex phenomena of technological innovation. We argue that no single model captures all of the dimensions and stylised facts of innovative learning. One must therefore distinguish between the various contributions according to the particular dimensions of the learning process which they explore. Their character also reflects the particular schools of thought to which the modellers adhere. Finally, we distinguish between the process of learning and adaptation within static environments, and those processes within dynamic environments where the introduction of new artefacts and patterns of behaviour change the selective pressure faced by agents.

Learning occurs in situations where agents have an imperfect understanding of the environment in which they operate. One can conceptualise this as operating under a number of different circumstances, according to the nature and complexity of the problem faced. Unfortunately, mainstream neo-classical economics has overwhelmingly focused on the simplest case of all. The principle method is to specify an equilibrium, moving or stationary, and to identify the dynamics of perturbations around that equilibrium. Each agent is assumed to understand the basic structure of the world. (S)he can establish the entire set of possible events and can in principle calculate the optimal course of action that must be taken, using some yardstick of utility. The central problem facing agents is the gathering of information, subject to resource constraints, regarding the parameters of the world in order to eliminate systematic forecasting errors (Sargent, 1993, p.21). While very familiar and very powerful in economics, this neo-classical method has two important drawbacks. Firstly, there is the problem of multiple equilibria, which are likely to arise in the presence of increasing returns (whether in production, technological adoption or consumption) ${ }^{1}$. Secondly, the response to perturbations close to equilibrium may be qualitatively different to perturbations which take the system far from equilibrium.

\footnotetext{
${ }^{1}$ Increasing returns and its ability to wreck neo-classical economic theory were discussed by Hicks and Sraffa in the famous 'cost controversy' of the 1920s and 1930s. See Prendergast (1992) for a useful account of this controversy.
} 
This mode of analysis, together with its underpinning assumptions regarding the cognitive capabilities of individual agents, has come under strong criticism from analysts working in the field of technological innovation (see for example Nelson, 1995; Silverberg, 1988; Silverberg and Verspagen, 1994a; and Winter, 1984). As well as observing the demanding assumptions made of agents regarding their ability to collect and process information, these analysts draw an important distinction between information gathering and the production of knowledge. Innovation is concerned with the generation of new solutions to new or established problems. For example, the problem-solving activity of firms involves the development of existing competences, through the generation of new products/services/processes, leading to new understandings and practices. Innovation alters the existing set of possible events, introducing new options that were previously unattainable and which could not be precisely forecast (Arrow, 1962a). Hence innovation is a very different activity to information gathering. Indeed, as Dosi (1988) argues, this process of search and discovery is a logical precondition to information processing. The attempt to characterise innovative activities as merely dealing with imperfect information, or asymmetric information for that matter, is therefore insufficient.

Partly in response to these criticisms, partly in order to solve internal paradigmatic problems such as multiple equilibria, a number of mainstream economists have begun to investigate a second, more realistic, scenario. In this second case agents do not have a perfect understanding of the underlying structure of their environment and, hence, do not share a common, mutually consistent, set of beliefs. Economic agents, as Sargent observes, must grapple with the same type of problems faced by economists; namely, the problem of estimating probability distributions and establishing causal relationships between the principle objects in their environment. Sargent himself has advocated the use of various simulation techniques - such as genetic algorithms, neural nets, genetic programming and classifier systems - in order to tackle problems which are not amenable to traditional analytic and statistical methods. Specifically, Sargent is interested in examining co-ordination problems and adaptive learning in complex environments, defined as environments that are multi-dimensional and inherently non-linear. The intended objective of this research agenda is to show that adaptive learning will indeed lead to co-ordination and convergence on some (pre-defined) optimal equilibria solution, and hence that the traditional analytic models of mainstream economics are useful as a first approximation.

It should be noted that the research agenda outlined by Sargent continues to be couched in terms of solving optimisation problems within a complex but static environment. Simulation models in this mode include Marimon, McGrattan and Sargent (1990), Arifovic (1994), and Bullard and Duffy (1998). For example, the Marimon, McGrattan and Sargent paper is concerned with intertemporal co-ordination games in which buyers and sellers are free to either trade or hold on to goods (at a fixed cost). They are interested to establish whether one particular good, which they call 'money', emerges which acts as a means of solving intertemporal production-consumption plans amongst multiple agents (i.e. an agent can temporarily hold on to money as a store of value and avoid the 'double coincidence of wants' problem). Consumer preferences, artefact characteristics, production techniques and costs do not change in this model. Yet multiple equilibria can arise even within the simple, static game model set up by Marimon et al. Therefore a second issue which they address is whether the introduction of artificial intelligence, in this case via agents using a classifier system, facilitates convergence to an optimal NashMarkov equilibrium. 
This basic approach contrasts sharply with that of neo-Schumpeterian economists who argue that a central problem in innovation systems is how agents improve their blurred and imprecise understandings of changing market relationships, organisational forms, relations of production, political regimes and other social structures. As Schumpeter observed, innovation is itself an act of creative destruction. The introduction of new economic artefacts, and the generation of new knowledge which underpins them, destroys preexisting knowledge bases and understandings. The problems facing learning agents in situations where the environment is itself subject to change is clearly more challenging than that considered by mainstream economists such as Sargent, Marimon and Arifovic in their simulation models. Indeed the study of innovation in dynamic environments has led neo-Schumpeterians such as Silverberg, Metcalfe and Dosi to suggest that one must also break with the traditional equilibrium method itself. Their advocacy of a more 'evolutionary' epistemology to innovation studies reflects the problems which the analysts themselves have experienced in studying innovation in dynamic, complex environments. It is to the simulation models developed by this research school that we turn our attention ${ }^{2}$.

There are two ways in which one can conceptualise learning and adaptation in dynamic, changing environments. In the simplest case one may assume the signals from a changing environment to be exogenously generated. This, we shall see, is the typical case in the majority of simulation models developed to date. Only recently have some scholars begun to consider an explicitly co-evolutionary perspective in which the selection environment is endogenised in order to examine the mutual interaction of actions, learning and environment.

Before moving on, we observe that learning in the social and biological domains is distinguished by the presence, in the former instance, of conscious goal-seeking behaviour that is guided by mental models of the world in which agents operate (Lumsden and Wilson, 1981; Boyd and Richardson, 1985). Consequently notions such as Lamarck's 'inheritance of acquired characteristics' have a relevance in the social systems which they do not in natural systems. In Biology the suggestion that behaviours acquired through individual experience can be transmitted to future generations is discredited (Gould, 1980; Mayr, 1982). However in the social and economic sphere a variety of institutional and cultural devices permit the codification and transmission of acquired experience through time (Hodgson, 1993). Not only will agents seek to alter their behaviour in order to improve their chances of success, they actively seek to affect selection environments in their favour. For example, firms launch new products and develop new production processes in order to improve their probability of success. Rather than accepting the random, exogenously given outcomes of a die, agents are aware that they operate within co-evolutionary environments and can, potentially at least, alter the value of the die being thrown and load them in their favour.

\footnotetext{
${ }^{2}$ Given the strict focus of the current paper on simulation models, it is not possible to consider other contributions made by the neo-Schumpeterian school to this field. The interested reader is therefore directed to more general overviews by Nelson (1995) and Silverberg and Verspagen (1995).
} 
The use of computer simulation is well established within the neo-Schumpeterian school, dating back to the pioneering work of Nelson and Winter (1982). As with those who followed them, Nelson and Winter turned to computer simulations as a practical means of exploring research questions which required the construction of complex formal models in their case they wished to examine the simultaneous existence of multiple firms and different search behaviours. Simulation models of innovation developed by the neoSchumpeterian school fall into two basic categories. One group of models investigates the relationship between innovation and the emergence of new technologies, markets and industry structures; typically taking the product life cycle as their theoretical starting point. The second group of models, by contrast, is concerned with macro issues, investigating the relationship between technological change and aggregate economic performance. Each of these areas requires examination as this helps identify some of the key stylised facts of learning which they have sought to capture.

Life cycle discussions of technological innovation at the micro and meso levels began with Abernathy and Utterback's seminal 1975 paper. At its theoretical core lies the dominant design concept. It is hard to underestimate the influence of this theory. Perhaps more than any other, it has been the organising principle around which the vast majority of theoretical and empirical work on innovation has been based over the last twenty years. Life cycle theory has been taken up by economists interested in the emergence of market led, de facto standards and their consequences for industry structure and economic welfare. It has found favour with a number of leading strategic management theorists, such as Andrews and Porter, as a device for informing strategic decisions concerning market positioning and the management of innovation. The empirical work conducted within this framework tends to focus the technical aspects of new products, the detailed analysis of which is usually tied to a discussion of how firms' competitive strategies are related to those technical aspects. In this way firms are accorded an elevated status, usually justified on the grounds that it is they who are principally responsible for $\mathrm{R} \& \mathrm{D}$ activities and for the introduction of new product innovations. The dominant design concept has also found favour amongst scholars engaged in simulation work using replicator-dynamic algorithms. Besides those working in the field of economics, these algorithms have been applied in socio-biology, macromolecular evolution, population ecology and games theory.

One can find both deterministic and stochastic versions of the replicator dynamic in this literature. While models containing deterministic versions of the replicator can be solved using conventional analytic methods, models containing stochastic versions need to be solved using computer simulation techniques. A brief consideration of the deterministic version of the algorithm is useful to give a general flavour of both. Following Silverberg (1988), the basic deterministic equation is derived from R.A. Fisher's mathematical formulation of natural selection (Fisher, 1930);

$$
\begin{aligned}
& \left.\mathrm{x}_{i}=\mathrm{Ax}_{\mathrm{i}}\left[\mathrm{E}_{\mathrm{i}}-<\mathrm{E}\right\rangle\right], \quad i=1 \ldots \mathrm{n} \\
& \text { where }\langle\mathrm{E}\rangle=\Sigma \mathrm{x}_{\mathrm{i}} \mathrm{E}_{\mathrm{i}}
\end{aligned}
$$

The population is composed of $n$ distinct competing 'species'. $\mathrm{x}_{i}$ represents the proportion 
of species $i$ in some population of interacting species and $\mathrm{E}_{\mathrm{i}}$ its related reproductive fitness. $\langle\mathrm{E}\rangle$ is the reference average fitness level of the species. A species with above-average fitness will grow in relative importance while those with below-average fitness will contract. The average fitness of the population is itself a moving target because $\langle E\rangle$ in turn changes in response to changes in species frequencies.

A quite simple and straight forward connection can be made with models investigating the emergence of dominant designs. If the $\mathrm{E}_{\mathrm{i}}$ 's are simple constants then it can be shown that the species with the highest fitness will displace all the others and that average fitness will increase monotonically over time. By taking equation (1) and giving economic interpretations to its primary components, Neo-Schumpeterians have applied the equation to the study of market selection and relative product competitiveness (typically defined as a combination of price, quality, delivery schedules, advertising and other variables).

The difference between the deterministic and stochastic versions lies in the former's assumption that selection operates over a population of unchanging objects which are given at the outset. Models by Soete and Turner (1984), and Metcalfe and Gibbons (1989) are notable exemplars of the former type. Working with an initially complete set of alternative product designs, these models indicate that market selection will work to reduce the number of surviving designs until, in the limit, there is convergence to a single, 'dominant' design. What is more, the market mechanism will select that design which is optimal for a given set of consumer preferences and production constraints. The result is an economic parallel to Fisher's 'Fundamental Theorem of Natural Selection' (Metcalfe 1984).

A stochastic version of equation (1) lies at the heart of Nelson and Winter's simulation model. This model embodies the three basic principles of an evolutionary approach which characterises all subsequent neo-Schumpeterian simulation models. These are variety across a population of agents (production techniques in the Nelson and Winter model), a selection mechanism related to the economic environment in which the population operates, and one or more mechanisms (typically mutation in the form of technical innovations) for generating novelty in the population.

The general approach of Nelson and Winter is also notable in that their simulation model attempted to provide a microeconomic foundation, based on firms' behavioural search for more efficient production techniques, that could explain a set of observed macroeconomic phenomena. Thus, rather than operating on product characteristics, the selection process is largely driven by the rate of return on alternative techniques of production (i.e. particular combinations of labour and capital inputs). Assuming that each firm operates one particular production technique, selection simultaneously operates on firms and techniques. In this way one can equate firms with phenotypes and techniques with genotypes.

Innovation is equated with the search for a more efficient production technique within a given and finite pool of techniques, which is specified at the outset. At any point in time, some of the feasible techniques are known, while others remain to be found in the future. Following Herbert Simon (1988), search activities reflect satisficing behaviour. In the Nelson and Winter model this means that firms will only engage in search if their rate of 
return falls below an arbitrarily set value of $16 \%$. If this condition arises then a firm may engage in one of two types of search - local search or imitation.

In the first case, firms search for previously undiscovered techniques. The probability of discovering a new technique declines linearly according to its technological distance from the technology originally employed (hence the term local search). By varying the skewness of this distance function, a labour or a capital bias can be introduced into the search process. Imitation, the second type of search process found in the Nelson and Winter model, involves a firm adopting a technique that is already employed by other firms. So, while the adoption of this technique is not new to the population, it does imply the development of new knowledge bases by the adopting firm. In the Nelson and Winter model, the probability of successful imitation is proportional to the share in output of each technique. The type of search activity that is undertaken is treated as a random event in the model, with a fixed probability given to each type. Even if search proves successful, a firm will only adopt a new technique if its expected rate of return is greater than the rate of return on its existing technique. Since firms do not have perfect foresight, their expectations are subject to error. Thus, as noted earlier, the selection process in the Nelson and Winter model is largely driven by the rate of return on techniques. Due to the complexity that arises from the simultaneous existence of multiple firms with different search behaviour, the Nelson and Winter model is analysed by means of computer simulations.

Neo-Schumpeterians have followed the Nelson and Winter approach of using computer simulations to evaluate growth models which have quite complicated firm-level micro foundations. A number of these scholars have sought to build on the original Nelson and Winter framework, introducing more realistic representations of technology in order to extend the analysis to consider other firm strategies concerning R\&D strategies and price setting. Neo-Schumpeterian models of economic growth adopt a rather different tact. These seek to avoid complicated firm-level descriptions, reflecting a desire to keep the complexity of the simulation model within bounds so that, for example, extensions to a multi-country context (Verspagen, 1993), or a more systematic analysis of the closed economy case (Silverberg and Lehnert, 1993, 1994), becomes easier. These models continue to share the same basic principles of the evolutionary approach - namely, population variety, selection and a variety generation mechanism - and employ computer simulation to facilitate an analysis of models which would otherwise be analytically intractable. In this context it is interesting to note that the Nelson and Winter model was originally stimulated, not by life cycle analysis, but by earlier macroeconomic discussions of growth. Indeed Nelson and Winter calibrated their model for the Solow (1957) data on U.S. total factor productivity over the first half of the twentieth century ${ }^{3}$.

\footnotetext{
${ }^{3}$ The stylised facts which emerge from this and other national studies (see Verspagen, 1995; and Verspagen and Wakelin, 1997 for recent reviews) focus on the aggregate time path for the variables capital, labour input, output (GDP), and wages (or labour share in output).
} 
The growing body of literature discussed above primarily focuses on firm-based learning, with the central consideration being given to the organisational and technological renewal of firms, and hence in their continuing ability to compete and survive. Having said this, different models emphasise different aspects of organisational learning. This is perhaps not very surprising given that learning in firms is a complex, multi-level concept that encompasses a variety of motives, sources, processes and outcomes. There are thus a number of 'stylised facts' on technological learning and innovation that arise and which neo-Schumpeterians have variously sought to explain within their models.

Following Nelson and Winter (1982), learning can be described as the ways in which firms build, supplement and organise knowledge and routines around their competences and within their different environmental cultures. Competences are the focused combination of resources within a firm which define its business activities and comparative advantage. In the face of changing competitive environments, learning is an essential pre-requisite for adaptation and success. Indeed the greater the environmental uncertainty facing firms, the greater the imperative for learning and innovation. This is particularly true of the kind of turbulent competitive environments characteristic of stage $\mathrm{I}$ in a product life cycle. Learning is thus a purposive quest on the part of firms to improve, or at the very least retain, their competitiveness.

A number of neo-Schumpeterian models have begun to explore the 'disembodied' features of technological innovation which can reside in (tacit) human skills, organisational competences or societal capabilities. While empirical research in this area remains limited, some facets of social and organisational learning are beginning to emerge. Learning is not only multi-faceted and complex, it can also entail tricky dilemmas between exploitation and exploration (Clark, Hayes and Lorenz, 1985; March, 1991). There exists a tension between the search for allocative efficiency, on the one hand, and dynamic efficiency on the other. The former seeks to incrementally improve an existing set of skills and knowledges. Here processes involving learning by doing (Arrow, 1962b) and learning by using (Rosenberg, 1982) are found to play an important role. By contrast, the search for dynamic efficiency involves an exploration and development of new knowledge bases, leading to the gales of creative destruction described by Schumpeter. Both aspects are present in the simulation models discussed in section 3. Indeed some models attempt to capture features of both. For example, learning by doing is a key feature of models such as Silverberg, Dosi and Orsenigo (1988) and Eliasson (1985), and is virtually a standard feature of neo-Schumpeterian growth models ${ }^{4}$.

Another factor which has received attention is the diffusion of technological knowledge between firms, i.e. technological spillovers due to the inability of innovating firms to fully appropriate all of the returns to R\&D effort. Perhaps the most notable treatment is provided by the simulation growth model of Silverberg and Verspagen (1994a and 1994b). Silverberg and Verspagen find that by varying parameters such as technological opportunity, $R \& D$ spillovers and mutation and imitation rates of the R\&D strategies, there are systematic variations in the level of technical progress and market concentration

\footnotetext{
${ }^{4}$ Learning by doing has also become central to much of the recent neo-classical endogenous growth literature (cf Romer, 1986; and Aghion and Howitt, 1992).
} 
consistent with economic intuition. The model of Silverberg, Dosi and Orsenigo (1988) is also of interest, as it analyses the effects due to a combination of learning by doing and technological spillovers. The net effect of both phenomena tends to be some form of increasing returns to adoption, akin to that described by Arthur (1988).

Learning is a non-trivial exercise whose benefits are unpredictable and unevenly distributed (March, 1991). Learning from failure can be as important as learning from success, and (perhaps the most difficult trick of all) agents are often required to unlearn existing behaviours in the act of developing new behaviours and competences (Hedberg, 1981). Despite these difficulties agents do learn, individually and collectively within various social institutions. In conditions of rapid and disruptive market and technological change, firms must go beyond the incremental improvement of existing competences associated with learning by doing and learning by using.

Explorative learning requires self-reflection and a questioning of the validity of current competences. However studies conducted in the management, innovation and economics literatures point to the often conservative and constrained nature of firms operating in highly uncertain, competitive environments. Dosi (1982) seeks to resolve this apparent paradox by pointing out the path-dependent nature of firms' learning and the extent to which their technological choices are constrained by 'technological trajectories'. Other authors have highlighted the extent to which the adoption of new strategies and structures depends on the activities of key individuals such as 'technological gatekeepers' (Michael, 1973), executive succession (Tushman et al, 1986) and through recruitment and training programmes (Dodgson, 1996).

The neo-Schumpeterian life cycle and growth models discussed above highlight the role of imitative search in the diffusion of new technological knowledge, although the details of how this is done tend to very considerably. What is more, they tend to focus on different aspects of the learning process. Some follow Nelson and Winter in focusing on the imitation of production techniques. Others have honed in on the imitation and diffusion of price-setting behaviours (e.g. Dosi, Marengo, Bassanini and Valente, 1994) or product characteristics (e.g. Windrum and Birchenhall, 1998).

Some important differences between models are due to the type of search algorithms that are employed. Such differences can cut across the neo-classical and neo-Schumpeterian distinction described earlier. For example, neo-classical and neo-Schumpeterian models which use a variant of the replicator-dynamic algorithm implicitly assume that imitation involves the wholesale adoption of production techniques or products developed by another firm. By contrast, models that employ genetic algorithms or GA-type algorithms, such as Lindgren (1991), Arifovic (1994), Birchenhall, Kastrinos and Metcalfe (1997) are able to consider the partial emulation of particular characteristics as well as wholesale imitation. The same is true for genetic programming (cf. Lane, 1993; Dosi, Marengo, Bassanini and Valente, 1994; Price, 1997) and classifiers (cf. Marimon et al, 1990; Vriend, 1995; Marengo and Tordjman, 1996). This opens the way for a consideration of the problems which arise when firms try to integrate new behaviours within an existing set of competences, although the author is unaware of an existing model that actually examines this. 
The evolutionary process would soon end if selection only had a given set of alternatives on which to operate. Thus neo-Schumpeterians pay considerable attention to the manner by which new innovations are generated by firms. In the simulation models that we have considered, innovation is treated as a stochastic process. As Silverberg and Verspagen (1995) note, this reflects a general consensus that stochasticity captures the uncertainty of the link that exists between innovative efforts and final outcomes.

Over the last decade much attention has been paid to the consequences of incremental learning, increasing returns and path dependency. Empirical studies conducted by, amongst others, Paul David (1985), Brian Arthur (1988), Sydney Winter (1984), Richard Nelson (1993), and Bengt-Ake Lundvall (1992) have highlighted their operation at the micro, meso and macro levels in case studies of individual firms, technologies, industries and national innovation systems. Agents build on their existing tacit knowledge bases and so their patterns of search involve the incremental construction of new competences within local knowledge domains. In the presence of increasing returns to adoption, path dependent learning can readily lead to a lock-in to sub-optimal technologies such as the QWERTY keyboard (David, 1985). What is more, small chance events (i.e. random and unpredictable) which occur in the early stages of a technology's history can fundamentally affect its development and diffusion. Arthur's investigation of the impact of such chance events in the car industry - where petrol, steam and electric battery engines were once rival technological options - is particularly insightful in this context (Arthur, 1988).

Various models have been proffered to capture the idea that changes in strategic choices are interdependent and so can spread through the economy as a result of changes in the behaviour of others (e.g. Arthur, Ermoliev and Kaniovski, 1987; Sharfstein and Stein, 1990; Banerjee, 1992; and Bikchnadani et al., 1992). These models indicate that lock-in to sub-optimal solutions can occur and that the final state is determined by initial conditions, i.e. it is path dependent. As Kirman (1997) notes, path dependency has been found to depend on two features of these models. First, it can arise when there is an increasing size of population (Arthur, Ermoliev and Kaniovski (1987), for example, assume an indefinitely increasing population to establish asymptotic results). The second factor is the strictly sequential nature of decision making. As Banerjee (1992) has shown, improved information does not necessarily lead to convergence on 'better' outcomes. What is more, in models where there are a fixed number of agents (e.g. Kirman, 1991; Feistel and Ebeling, 1989; and Bruckner, Ebeling, Jiménez Montaño and Scharnhorst, 1994) the limit situation may be a limiting distribution rather than convergence to a single state. Under these circumstances the system will not, even in the absence of exogenous disturbances, settle down to any one state.

While these behaviours contrast sharply with our earlier discussion of the replicator dynamic algorithm (equation 1), it is quite easy to link these two discussions ${ }^{5}$. Fisher's Law is only valid for constant fitness functions. In the event of frequency-dependent selection, where fitness depends on population shares (including a species' own share), a variety of quite different behaviour can arise. These behaviours include the emergence of multiple equilibria increasing returns and lock-in to sub-optimal solutions.

\footnotetext{
${ }^{5}$ For a more technical discussion of the different aspects of these approaches see Silverberg (1988) and Rosser (1991).
} 
Research into the embodied side of technological change (as represented by physical capital equipment) has a longer history and so its empirical and theoretical appreciations are rather more developed than its disembodied counterpart. For example, there is overwhelming evidence to support the proposition that technical change is highly constrained by investment in physical capital. Yet even in this area we find important differences in the formal treatments of embodied technical change.

The usual approach, adopted by neo-classicals and neo-Schumpeterians alike, employs a vintage concept of embodied technology. It is assumed that there is a single best-practice technology at any given time and that all current investments are made in this technology. At any one time the capital stock comprises various vintages going back in time. The technological lifetime of capital equipment is defined by a specified scrapping margin, governing the oldest permissible vintage due to technological obsolescence and/or wear and tear. The aggregate capital stock is then a sum or integral (in the discrete and continuous time cases, respectively) over the vintages during this technological lifetime, and average technical coefficients (labour productivity, capital/output ratios) are the corresponding vintage-weighted sum or integrals.

While vintage capital stock is relatively easy to compute from data, the approach contains two disadvantages which detract from its realism and tractability. The first is the assumption of a single best-practice technology. This effectively rules out multiple competing technologies at the investment frontier, conflicting with the body of literature developed within the life cycle tradition. Silverberg, Dosi and Orsenigo (1988) have overcome this problem to some extent by assuming a fixed set of vintage structures, of which multiple distinct technologies may co-exist in their model. Silverberg and Verspagen (1995) note that a second problem with the calculation of discrete-time vintage capital stocks can lead to awkward mathematical complications when they are embedded in a dynamic framework with endogenous scrapping.

A 'quasi-vintage' framework has been employed in the analytic models of Metcalfe (1988), Iwai (1984a, 1984b), Henkin and Polterovich (1991), and the simulation models of Silverberg and Lehnert (1993, 1994) and Silverberg and Verspagen (1994a, 1994b). Here capital vintages are labelled by their type rather than their date of acquisition and so only their technical characteristics are relevant (service age no longer plays a role). This opens the way for several qualitatively distinct technologies to diffuse simultaneously through the capital stock. Silverberg and Verspagen (1995) observe that the inability to track vintages by their chronological age is more than offset by the gain in realism and considerable mathematical simplification. Indeed they note that quasi-vintages more naturally lend themselves to the kind of multiple replacement dynamics investigated by Marchetti and Nakicenovic (1979), Nakicenovic (1987), and Grübler (1990). 
As there is no single model which captures all of the dimensions and stylised facts of innovative learning - given the complexity of the subject matter this is hardly surprising - it would be useful to develop a taxonomy which distinguishes between the various contributions which have been made. Building on initial suggestions made by Dosi (1996), the first dimension of such a taxonomy should distinguish between models where a static set of possibilities is determined at the outset (Type I models) and open-ended search models where new objects - product characteristics, production processes etc. - may be discovered (Type II models). The other key dimension is the principle 'mode of learning' that is highlighted by the simulation models, or, to be more accurate, the restrictions which are placed on the domain of innovative learning by their authors.

\section{Table 1 and Table 2 here}

As noted earlier, some quite fundamental distinctions exist between the models developed by economists adhering to neo-classical and neo-Schumpeterian schools of thought. Neoclassical work in this area has concentrated on the development of Type I models. This reflects their principal concern with solving the problem of multiple equilibria. Two distinct domains of learning have been investigated in this regards by neo-classical modellers; inference models and action/strategy models. However the research question remains the same in both cases; namely, 'how do agents select between a set of equilibria and converge to one particular (optimal) solution'?

Inferential learning by individuals has been modelled as the identification of an optimal decision rule using Bayesian updating processes. In both single and multi-agent situations it is typically assumed that the state of the world $s$ is given, subject to some stochastic noise, and that the agents have to select an appropriate action in each period $t$. This involves each agent producing an estimate of the stochastic process and computing the expected utility associated with a particular action $a$. Each agent has an initial distribution $\partial$. This is updated using a Bayesian rule which generates a new distribution $\partial^{l}$. In the single agent situation this takes into account the observed payoff of the action and the outcome of the stochastic process in the previous period (Feldman, 1991). In multi-agent situations this must also take into account the actions of the other players (Kalai and Lehrer, 1993). Convergence to equilibrium occurs in the limit when the distribution of $\partial^{1}$ converges to the real distribution $s$. However convergence only occurs when agents attach a positive probability to events contained in $s$. Convergence will not occur if agents do not attach a positive probability to these events, or if they attach a positive probability to events not contained in $s$ - the so-called 'grain of truth' condition (Kalai and Lehrer, 1993). Feldman (1991) has also shown that $\partial^{1}$ cannot be generated if $a$ is non-numerable.

Bayesian learning is highly demanding in terms of the common knowledge that is attributed to agents. Each agent must know all possible outcomes of the world and the complete set of actions which may be taken. Less demanding assumptions are made of individual cognition in 'evolutionary' games models. These introduce an external selection mechanism that operates over a finite set of possible actions. Replicator-type algorithms of the form in equation (1) are commonly used to model the selection 
mechanism. The simplest implementation assumes that each agent within a population has one action strategy which is given at the outset. Selection rewards those actions which are relatively fit. Rather than being endowed with just one action, each agent may have a fixed menu of actions. As before, an exogenous selection mechanism diffuses those actions which have proved successful in the past (cf. Fudenberg and Kreps, 1993; Kaniovski and Young, 1994).

Simple replicator set ups do not entirely solve the multiple equilibria problem. For example, the system can converge on a sub-optimal equilibrium solution if there is an initially incomplete set of alternative actions. A popular means of dealing with this problem is to add a stochastic mutation operator that generates new strategies within the population (e.g. Kandori, Mailaith and Rob, 1993; Foster and Young, 1990; and Fundberg and Harris, 1992). It should be noted that this use of mutation differs significantly to its earlier use by Maynard Smith (1982). Rather than modelling mutation as an ongoing process, Maynard Smith used mutation as a device for studying the evolutionary stability of equilibria. An equilibrium is said to be an evolutionary stable strategy (ESS) if, once achieved, it cannot be disturbed by a small proportion of mutations appearing in the system. Still, the introduction of stochastic mutation is not a panacea for problems of multiple equilibrium or convergence. To begin with, a high rate of stochastic noise impedes the overall efficiency of the search process (Sargent, 1993). Furthermore, even with the introduction of a mutation operator, a system can still continue to oscillate in the limit between a number of different states where there is a finite population of agents (Benaim and Hirch, 1994; Posch, 1997).

Criticism may also be levelled at the representation of individual cognition in these models. One needs to distinguish between Bayesian information processing models and evolutionary games models with the class of 'adaptive learning' models developed by Marimon et al. (1990), Arifovic (1994), and Bullard and Duffy (1998). The former group does not concern itself with how agents learnt about the 'true model' of their environment or, in games theory, the extensive form of a particular game. One is presented with a 'dumb' agent who does not reflect on his/her course of action and does not consider different possible states of the world. They are simply 'selected upon'. Learning can only be said to occur at the population level when no change occurs at the level of the individual. The latter group of adaptive learning models at least allows for the development of new behaviours as agents adapt to, and learn about, their static environments.

The criticism most frequently levelled against these Type I models by neo-Schumpeterians focuses on the assumption that a given set of pre-existing objects are present in the environment from the outset. Bounded rationality in static environments is thus largely concerned with problems of imperfect information and probabilistic risk. It is assumed that agents are endowed with appropriate algorithms to represent the environment and evaluate alternative courses of action. Neo-Schumpeterians have themselves investigated Type I scenarios, most notably in realised performance models. However their interest is confined to those cases where allocative efficiency may improve through learning by doing, learning by using and other processes involving the repetition of unchanging actions. These search processes are concerned with the exploitation of an existing set of competences and, as such, are quite different to processes of technological innovation and change which is the primary research interest of this particular group of economists. 
Following Schumpeter, they conceive of technological change as an inherently dynamic process - one of 'creative destruction' in which agents seek to develop new knowledge bases and competences. This is the search for dynamic, as opposed to allocative, efficiency.

We have previously discussed the Type II simulation models developed by neoSchumpeterians in great detail. It is sufficient, therefore, to reiterate that these models are very different in character to the Type I models investigated by neo-classicals. Three distinct domains of learning have been investigated by neo-Schumpeterian simulation models; open-ended technological search, behavioural search and co-evolutionary learning across multiple populations. Open-ended technological search in dynamically changing environments is a consequence of two factors. The first is the introduction of novelty and the generation of new patterns of behaviour which are themselves a force for learning and adaptation. This is conceptually different to the process of adaptation under a constant and unchanging selection pressure. Through the dynamic interplay between novelty generation and market selection mechanisms, it is likely that the economic system will be far from equilibrium. Those aggregate regularities which do appear are emergent properties that arise from these dynamic, out-of-equilibrium interactions between market selection and variety. Second, heterogeneity amongst agents, and the complexity of inter-agent interactions, are the norm rather than the exception in Type II circumstances. This highlights the transient, as opposed to durable, nature of the convergence states that emerge from these dynamic interactions.

The concept of bounded rationality also takes on a quite different meaning in Type II settings. Agents will face problems, not with respect to their powers to collect and process information, but also to the algorithmic complexity of the problem faced and their ability to define preferences over expected actions, events and outcomes (Simon, 1988). Not only must agents update their information and knowledge bases, they must also alter their rules of learning over time. This additional complexity of the learning process is evident in the behavioural search models of Type II environments that are the counterparts to the actionstrategy models of Type I environments.

Finally, we note that an important distinction needs to be drawn between models where changing selection environments are driven by 'exogenous shocks', and the endogenous co-evolution of learning and selection environments where the technological, behavioural and organisational innovations of adaptive agents impact upon, and alter, the selection environment in which they operate. Despite the professed aspiration to deal with the latter, very few attempts have been made to explore the co-evolutionary dynamics of multiple populations using simulation models. To this end the model developed by Windrum and Birchenhall (1998) considers the case where the accumulation of technological knowledge by firms is shaped by the market selections made by consumers. Consumer preferences are not fixed but change and evolve over time in response to launch of new innovative products, sometimes in quite unforeseen ways. Therefore the model considers the manner in which consumer preferences co-evolve with firms' learning with respect to the characteristics of the products offered for sale. The model is used to critically reappraise the dominant design argument that lies at the heart of the life cycle model of technological innovation. Convergence to a single dominant design is a special case in this model while multiple product niches are permissible under a wide range of conditions. 


\section{Summary}

Four key issues have been identified when reviewing the burgeoning simulation literature on technological innovation. Firstly, the increasing use of computer simulations in this field is predominantly driven by a desire (some would say a real and pressing need) to develop a class of models that can deal with the complex phenomena that are characteristic of technological innovation. Increased access computer simulation tools has therefore facilitated the exploration of complex issues which were previously intractable using more traditional analytical methods. Secondly, no single model captures all of the dimensions and stylised facts of innovative learning. Indeed one can usefully distinguish between the various contributions according to the particular dimensions of the learning process which they explore. To this end a taxonomy of simulation models has been offered which organises the various contributions according to the types of learning which have been studied. This taxonomy enables one to clarify some of the basic distinctions underpinning the contributions made by mainstream neo-classical economists and neo-Schumpeterian economists.

A related, third point highlighted by the paper is the degree to which the character of the various contributions reflect by the generic research questions of these quite different schools of thought. Finally, attention has been drawn to an important distinction between processes of learning and adaptation within a static environment and those in dynamic environments, where the introduction of new artefacts and patterns of behaviour change the selective pressure faced by agents. In choosing explore one or other of these settings, simulation modellers adhering to one or other school of thought reveal quite different conceptual understandings of technological innovation. 


\begin{tabular}{|c|c|c|c|}
\hline \multirow[t]{2}{*}{$\begin{array}{l}\text { TYPE I } \\
\text { models }\end{array}$} & $\begin{array}{l}\quad \text { Inference models } \\
\text { - } \quad \begin{array}{l}\text { Bayesian updating of decision } \\
\text { rules }\end{array} \\
\text { (e.g. Feldman, 1991; } \\
\text { Kalai and Lehrer, 1993) }\end{array}$ & $\begin{array}{l}\text { Actions/strategies models } \\
\text { - 'evolutionary' games } \\
\text { (e.g. Fudenberg and Kreps, 1993; } \\
\text { Kaniovski and Young, 1994) } \\
\text { - } \quad \text { innovation-adoption models } \\
\text { (e.g. Arthur, Ermoliev and } \\
\text { Kaniovski 1987) }\end{array}$ & $\begin{array}{l}\text { Realised performance models } \\
\text { - learning-by-doing and using } \\
\text { (e.g. Silverberg et al, 1988) }\end{array}$ \\
\hline & $\begin{array}{r}\text { Adaptive models in stc } \\
\text { (e.g. Marimon et al., 1990; Arifovi }\end{array}$ & $\begin{array}{l}\text { tionary environments } \\
\text { c, 1994; Bullard and Duffy; 1998) }\end{array}$ & \\
\hline
\end{tabular}

Table 1. Type I simulation models of technological innovation

\begin{tabular}{|clll|}
\hline & \multicolumn{1}{c}{ Open-ended search models } & \multicolumn{1}{c|}{ Behavioural search models } & \multicolumn{1}{c}{ Co-evolutionary learning models } \\
& (e.g. Nelson and Winter, 1982) & (e.g. Lindgren, 1991; & (e.g. Windrum and Birchenhall, \\
TYPE II & & Silverberg and Verspagen, & 1998) \\
models & & 1994b; Dosi, Marengo, & \\
& & Bassanini and Valente, 1994) \\
\hline
\end{tabular}

Table 2. Type II simulation models of technological innovation 


\section{Bibliography}

Abernathy, W.J. and Utterback, J.M., 1975, 'A dynamic model of product and process innovation' Omega, 3, pp.639-656.

Aghion, P. and Howitt, P., 1992, 'A model of growth through creative destruction', Econometrica, 60, pp.323-351.

Arifovic, J., 1994, 'Genetic algorithm learning and the cobweb model', Journal of Economic Dynamics and Control, 18, pp.3-28.

Arrow, K., 1962a, 'Economic welfare and allocation of resources for innovation' in N. Rosenberg, (ed.), The Economics of Technological Change, Penguin: London

Arrow, K., 1962b, 'The economic implications of learning by doing', Review of Economic Studies, 29, pp.155-173.

Arthur, W. B., 1988, 'Self-reinforcing mechanisms in economics', in P.W. Anderson, K.J. Arrow and D. Pines, (eds.), The Economy as an Evolving Complex System, Addison-Wesley: Reading, Mass.

Arthur, B., Ermoliev, Y. and Kaniovski, Y., 1987, 'Path dependent processes and the emergence of macrostructure', European Journal of Operational Research, 30, pp.294303.

Banerjee, A., 1992, 'A simple model of herd behaviour', Quarterly Journal of Economics, 108, pp.797-817.

Benaim, M., and Hirsch, W., 1994, 'learning processes, mixed equilibria and dynamical systems arising from repeated games', Mimeo, University Paul Sabatier, Toulouse.

Bikchnadani S., Hirschleifer, D., Welch, I., 1992, 'A theory of fads, fashion, custom and cultural change as informational cascades', Journal of Political Economy, 100, pp.9921026.

Binmore, K., 1990, Essays on the Foundations of Game Theory, Blackwells: Oxford.

Birchenhall, C., Kastrinos, K., Metcalfe, S., 1997, 'Genetic algorithms in evolutionary modelling', Journal of Evolutionary Economics, 7, pp.375-393.

Boyd, R. and Richardson, P.J., 1985, Culture and the Evolutionary Process, University of Chicago Press: Chicago.

Bruckner, E., Ebeling, W., Jiménez Montaño, M.A. and Scharnhorst, A., 1994, 'Hyperselection and Innovation Described by a Stochastic Model of Technological Evolution', in L. Leydesdorff and P. van den Besselaar, (eds.), Evolutionary Economics and Chaos Theory, Pinter: London. 
Bullard J. and Duffy, J., 1998, 'Using genetic algorithms to model the evolution of heterogeneous beliefs', Computational Economics, forthcoming.

Chiaromonte, F. and Dosi, G., 1993, 'Heterogeneity, competition, and macroeconomic dynamics', Structural Change and Economic Dynamics, 4, pp.39-63.

Clark, K., Hayes, R., and Lorenz, C., 1985, The Uneasy Alliance: Managing the Productivity Technology Dilemma, Harvard Business School Press: Cambridge, MA.

David, P., 1985, 'CLIO and the economics of QWERTY', American Economic Review, Proceedings, 75, pp.332-337.

Dodgson, M., 1996, 'Learning, trust and inter-firm technological linkages: some theoretical associations', in R. Coombs, A. Richards, P. Saviotti and V. Walsh, (eds.), Technological Collaboration: The Dynamics of Cooperation in Industrial Innovation, Edward Elgar: Cheltenham and Vermont.

Dosi, G., 1982, 'Technological paradigms and technological trajectories: a suggested interpretation of the determinants and direction of technological change', Research Policy, 3, pp.147-162.

Dosi, G., 1988, 'The nature of the innovative process', in G. Dosi, C. Freeman, R. Nelson, G. Silverberg and L. Soete, (eds.), Technical Change and Economic Theory, Pinter: London and New York.

Dosi, G., Marengo, L., Bassanini, A. and Valente, M., 1994, 'Norms as emergent properties of adaptive learning. The case of economic routines' IIASA Working Paper, WP-94-73, IIASA: Laxenburg, Austria.

Dosi, G.,1996, Discussion given at the conference 'Innovation, Evolution and Technology', MERIT, University of Limburg, 26 August 1996.

Eliasson, G., 1985, The firm and financial markets in the Swedish micro-to-macro model, IUI: Stockholm.

Feistel, R. and Ebeling, W., 1989, Evolution of Complex Systems, VEB Deutscher Verlag der Wissenschaften: Berlin.

Feldman, M., 1991, 'On the generic non-convergence of Bayesian actions and beliefs', Economic Theory, 1.

Fisher, R. A., 1930, The Genetical Theory of Natural Selection, Clarendon Press: Oxford.

Foster, D. and Young, P., 1990, 'Stochastic evolutionary game dynamics', Theoretical Population Biology, 38, pp.219-232.

Fudenberg, D. and Harris, C., 1992, 'Evolutionary dynamics with aggregate shocks', Journal of Economic Theory, 57, pp.420-441. 
Fudenberg, D. and Kreps, D., 1993, 'Learning mixed equilibria', Games and Economic Behaviour, 5, pp.320-367.

Gould, S.J., 1980, The Panda's Thumb, Penguin: London

Grübler, A., 1990, The Rise and Decline of Infrastructures. Dynamics of Evolution and Technological Change in Transport, Physica-Verlag: Heidelberg.

Hedberg, B., 1981, 'How organisations learn and unlearn', in P. Nystrom and W. Starbuck (eds.), Handbook of Organisational Design: Vol. 1, Oxford University Press: Oxford.

Henkin, G.M. and Polterovich, V.M., 1991, 'Schumpeterian dynamics as a non-linear wave theory', Journal of Mathematical Economics, 20, pp.551-590.

Hodgson, G., 1993, Economics and Evolution, Polity Press: London

Iwai, K., 1984a, 'Schumpeterian Dynamics. I: an evolutionary model of innovation and imitation', Journal of Economic Behaviour and Organization, 5, pp.159-190.

Iwai, K., 1984b, 'Schumpeterian Dynamics. II: technological progress, firm growth and 'economic selection”, Journal of Economic Behaviour and Organization, 5, pp.321-351.

Kalai, E. and Lehrer, E., 1993, 'Rational learning leads to Nash Equilibrium', Econometrica, 61, pp.1019-1045.

Kandori M., Mailath, G.J. and Rob, R., 1993, 'Learning, mutation and long run equilibria in games', Econometrica, 61, pp.29-56.

Kaniovski, Yu. and Young, P., 1994, Learning dynamics in games with stochastic perturbations, Games and Economic Behaviour, 11, pp.330-363.

Kirman, A., 1991, 'Epidemics of opinion and speculative bubbles in financial markets', in M. Taylor (ed.), Money and Financial Markets, Macmillan: London

Kirman, A., 1997, 'The economy as an evolving network', Journal of Evolutionary Economics, 7, pp.339-353.

Kwasnicki, W. and Kwasnicka, H., 1992, 'Market, innovation, competition: an evolutionary model of industrial dynamics', Journal of Economic Behaviour and Organization, 19, pp.343-368.

Lane, D., 1993, 'Artificial worlds and economics', Journal of Evolutionary Economics, 3, pp.177-197.

Lindgren, K., 1991, 'Evolutionary phenomena in simple dynamics', in C. Langton, (ed.), Artificial Life II, Addison-Wesley: Redwood City, CA.

Lumsden, C.J. and Wilson, E.O., 1981, Genes, Mind and Culture: The Coevolutionary Process, Harvard University Press: Cambridge, MA. 
Lundvall, B-A., 1992, National Systems of Innovation, Pinter: London

March, J.G., 1991, 'Exploration and exploitation in organisational learning', Organizational Science, 2, pp.71-87.

Marchetti, C. and Nakicenovic, N., 1979, 'The dynamics of energy systems and the logistic substitution model', IIASA Research Report, RR-79-13, IIASA: Laxenburg, Austria.

Marengo, L. and Tordjman, H., 1996, 'Speculation, heterogeneity and learning: A model of exchange rate dynamics', Kyklos, 47.

Marimon, R., McGrattan, E., and Sargent, T.J., 1990, 'Money as a medium of exchange in an economy with artificially intelligent agents', Journal of Economic Dynamics and Control, 14, pp.329-373.

Maynard Smith, J., 1982, Evolutionary and The Theory of Games, Cambridge University Press: Cambridge.

Mayr, E., 1982, The Growth of Biological Thought, Belknap Press: Harvard

Metcalfe, S., 1984, 'Technological innovation and the competitive process', in P. Hall, (ed.), Technology, Innovation and Economic Policy, P. Allen: London

Metcalfe, S., 1988, 'The diffusion of innovations: an interpretative survey', in G. Dosi, C. Freeman, R. Nelson, G. Silverberg and L. Soete, (eds.), Technical Change and Economic Theory, Pinter: London and New York.

Metcalfe, S. and Gibbons, M., 1989, 'Technology, variety and organisation' in Research on Technological Innovations, Management and Policy, Vol. 4, JAI press.

Michael, D., 1973, On Learning to Plan - and Planning to Learn, Jossey-Bass: San Francisco.

Nakicenovic, N., 1987, 'Technological substitution and long waves in the USA', in T. Vasko, (ed.), The Long-Wave Debate, Springer-Verlag: Berlin.

Nelson, R. (ed.), 1993, National Innovation Systems: A Comparative Analysis, Oxford University Press: Oxford

Nelson, R., 1995, 'Recent evolutionary theorising about economic change', Journal of Economic Literature, 33, pp.48-90.

Nelson R., and Winter, S., 1982, An Evolutionary Theory of Economic Change, Harvard University Press: Cambridge, Mass.

Posch, M., 1997, 'Cycling in a stochastic learning algorithm for normal form games', Journal of Evolutionary Economics, 7, pp.193-207. 
Prendergast, R., 1992, 'Increasing returns and competitive equilibrium - the content and development of Marshall's theory', Cambridge Journal of Economics, 16, pp.447-462.

Price, T., 1997, 'Using co-evolutionary programming to simulate strategic behaviour in markets', Evolutionary Economics, 7, pp.219-254.

Ricardo, D., 1817, On the Principles of Political Economy and Taxation, reprint 1951, P. Sraffa (ed.), Cambridge University Press: Cambridge.

Romer, P.M., 1986, 'Increasing returns and long-run growth', Journal of Political Economy, 94, pp.1002-1037.

Rosenberg, N., 1982, Inside the Black Box: Technology and Economics, Cambridge University Press: Cambridge

Rosser Jr., J.B., 1991, From Chaos to Catastrophe: A general Theory of Economic Discontinuities, Kluwer: Boston, Dordrecht.

Sargent, T.J., 1993, Bounded Rationality in Macroeconomics, Oxford University Press: Oxford.

Sharfstein, D., Stein, JK., 1990, 'Herd behaviour and investment', American Economic Review, 80, pp.205-231.

Silverberg, G., 1988, 'Modelling economic dynamics and technical change: mathematical approaches to self-organisation and evolution', in G. Dosi, C. Freeman, R. Nelson, G. Silverberg and L. Soete, (eds.), Technical Change and Economic Theory, Pinter: London and New York.

Silverberg, G., Dosi, G. and Orsenigo, L., 1988, 'Innovation, diversity and diffusion: a self-organisation model', Economic Journal, 98, pp.1032-1054.

Silverberg, G. and Lehnert, D., 1993, 'Long waves and 'evolutionary chaos' in a simple Schumpeterian model of embodied technical change', Structural Change and Economic Dynamics, 4, pp.9-37.

Silverberg, G. and Lehnert, D., 1994, 'Growth fluctuations in an evolutionary model of creative destruction', in G. Silverberg and L. Soete (eds.), The Economics of Growth and Technical Change: Technologies, Nations, Agents, Edward Elgar: Aldershot.

Silverberg, G. and Verspagen, B., 1994a, 'Collective learning, innovation and growth in a boundedly rational, evolutionary world', Journal of Evolutionary Economics, 4, pp.207-226.

Silverberg, G. and Verspagen, B., 1994b, 'Learning, innovation and economic growth: a long-run model of industrial dynamics', Industrial and Corporate Change, 3, pp.199223. 
Silverberg, G. and Verspagen, B., 1995, 'Evolutionary theorising on economic growth' in K. Dopfer, (ed.), The Evolutionary Principles of Economics, Kluwer Academic Publishers: MA.

Simon, H.A., 1988, Models of Thought, (Second edition), Yale University Press: New Haven.

Soete, L. and Turner, R., 1984, 'Technological diffusion and the rate of technical change', Economic Journal, 94, pp.612-623.

Solow, R., 1957, 'Technical change and the aggregate production function', Review of Economic Statistics, 29, pp.312-320.

Tushman, M., Virany, B. and Romanelli, E., 1986, 'Executive succession, strategic reorientation, and organisational evolution', in M. Hortwich (ed.), Technology in the Modern Corporation, Pergamon: New York.

Verspagen, B., 1995, 'Convergence in the world economy: a broad historical overview', Structural Change and Economic Dynamics, 6, pp.143-166.

Verspagen B. and Wakelin, K., 1997, 'International competitiveness and its determinants', International Journal of Applied Economics, 11, pp.177-190.

Vriend, N., 1995, 'Self-organisation of markets: an example of a computational approach', Computational Economics, 8, pp.205-231.

Windrum, P. and Birchenhall, C., 1998, 'Is life cycle theory a special case?: dominant designs and the emergence of market niches through coevolutionary learning', Structural Change and Economic Dynamics, 9, pp.109-134.

Winter, S., 1984, 'Schumpeterian competition in alternative technological regimes', Journal of Economic Behaviour and Organization, 5, pp.287-320. 